Ronksley-Pavia, M. L., \& Grootenboer, P. (2017). Insights into Disability and Giftedness: Narrative methodologies in interviewing young people identified as twice exceptional. In R. Dwyer, e. emerald, \& I. Davis (Eds), Storied Worlds: Diverse Case Studies of Narrative Research. Springer: Singapore.

\title{
Insights into Disability and Giftedness: Narrative methodologies in interviewing young people identified as twice exceptional
}

\author{
Michelle Ronksley-Pavia \\ Griffith University
}

Peter Grootenboer

Griffith University

Abstract

This chapter describes the fluid methodologies used in a narrative research study involving interviewing children identified as gifted and also having a disability - twice exceptional children. Within the qualitative literature encompassing young people identified as twice exceptional, there is limited discussion of interview techniques and protocols used by interviewers in obtaining their narrative data or field texts. The researchers often skim over this section with phrases like "semi-structured interviews were used to obtain data", with little detail surrounding the actual interview process, the creation of the field texts, and subsequent analysis. In order to guide ongoing research in the area of twice exceptionality, it is important to develop and explain the steps and processes used to obtain qualitative interview data with these young people, and further detail how this might be analysed through narrative methods. In this chapter we discuss the development of an interview protocol which was flexible and dynamic, and able to respond to the needs of both researcher and participant in conducting field research with one twice exceptional child. The focus of this chapter is on how we conducted the interviews, with some insights presented into our process of narrative analysis through description of one participant's narrative presented as a story constellation.

The interview protocol involved an inclusive approach where the child's needs were addressed to ensure they were able to participate in the project, regardless of their disability and any communication needs. Conducting the interviews in the child's home, a place of security, whilst spending time getting to know the child to 
build rapport, increased comfort during the interviews. This chapter concludes with reflecting on our flexible and dynamic interview approach which facilitated Ashley's sharing of her lived experiences of twice exceptionality.

\section{Introduction}

Twice exceptional children are young people who have been identified as gifted and also have a disability (Foley-Nicpon, Allmon, Sieck, \& Stinson, 2011). There has been limited research with these children and in particular, we know little about their lived experiences. This is perhaps partly due to the issues with collecting qualitative data with twice exceptional children. In this chapter we outline the theoretical perspectives of our qualitative research, and explore the development and use of our dynamic interview protocol in this narrative inquiry. First we describe the phenomenon under study, being the lived experiences of twice exceptional children. We then provide an example of one of the narrativeinformed case studies, discussing our narrative analysis through a story constellations' approach. This is undertaken by presenting examples of field texts (data) and the analysis of the story constellation which relates specifically to the lived experiences of one twice exceptional child, Ashley.

\section{Background}

Within the qualitative research literature encompassing young people identified as twice exceptional, there is limited discussion of interview techniques and protocols used by researchers in generating their data, or field texts. The researchers frequently skim over these details with phrases like "semi-structured interviews were used to obtain data", with little information about the actual interview process, the collecting and compiling of the field texts, and subsequent analysis. In order to guide ongoing research in the area of twice exceptionality, it is important to develop and explain the steps and processes used to obtain qualitative interview data with these young people, and to further detail how this might be analysed through the use of narrative methodologies. Through a narrative approach to the study the "social reality" that is shaped through social interaction in the children's contexts can be explored, identified and described (Polkinghorne, 1988).

The research project described in this chapter is part of a larger study relating to the first author's doctoral research which explored the lived experiences of twice exceptional children aged 9 to 16 years, in Queensland and northern New South Wales, Australia. The study explored discursive practices which twice exceptional children encountered in their lives and education. A fundamental issue 
confronting society and education systems is the exclusion and marginalisation of children with disability and those identified as gifted.

\section{Defining giftedness, disability and twice exceptionality}

Twice exceptionality covers a combination of both disability and giftedness, where disability may refer to any disability-sensory, physical, mental, and intellectual (Foley-Nicpon et al., 2011; Foley-Nicpon, Assouline, \& Colangelo, 2013; World Health Organisation, 2011), and where giftedness refers to "high cognitive abilities" (Gagné, 2009, p. 1). Yet defining these two terms is not this clear-cut and there are no universally accepted definitions of giftedness or disability. This lack of consensus leads to compounded problems in identifying children who are twice exceptional (Baum \& Olenchak, 2002). In 2014, a definition for twice exceptionality was proposed by meetings of the American National Commission on Twice exceptional Students and other interested parties, which sought to create an operational definition to guide research, planning and provision (Reis, Baum, \& Burke, 2014). This definition stated that:

Twice exceptional learners are students who demonstrate the potential for high achievement or creative productivity in one or more domains such as math, science, technology, the social arts, the visual, spatial, or performing arts or other areas of human productivity AND [original capitalisation] who manifest one or more disabilities as defined by federal or state eligibility criteria. These disabilities include specific learning disabilities; speech and language disorders; emotional/behavioral [sic] disorders; physical disabilities; Autism Spectrum Disorders (ASD); or other health impairments, such as Attention Deficit/Hyperactivity Disorder (ADHD). These disabilities and high abilities combine to produce a unique population of students who may fail to demonstrate either high academic performance or specific disabilities. Their gifts may mask their disabilities and their disabilities may mask their gifts. (p. 222)

In essence, twice exceptionality affects the whole child, including their life inside and outside school. They are first a child experiencing childhood and endeavouring to understand themselves and the world around them, with the added facets of trying to comprehend their disability and giftedness. To understand the lifeworlds of these students, the most obvious way to elicit children's experiences appears to be to talk with them, and so interviews seem to be the best research method to employ. 


\section{The Participants}

Despite the definitional issues outlined above, we had to identify and select participants for the study. To this end, research participants were sought by an expression of interest request sent through support groups for children and parents/carers, asking for children with identified disability and identified giftedness to participate. The participants consisted of eight children-five males and three females. In this chapter we concentrate on Ashley's story. Ashley is described towards the end of this chapter.

Although expressive language was advanced for chronological age amongst the participants, particularly Ashley, we needed to remain aware throughout the interview process, that due to their disabilities, some of the participants' receptive language skills may not be as well developed. Five of the eight participants had processing disorders which affected their receptive language skills and auditory processing abilities.

\section{Research Methodology and Methods}

A narrative informed case study approach offered the opportunity to interpret twice exceptional children's "reality" through their eyes. By exploring the lived experiences of these children this research endeavoured to gain an understanding of their notions of self and lived or constructed realities (DePoy \& Gilson, 2010). It was hoped that a better understanding of twice exceptional students' lives would have implications for improving policy, practice and 'management' related to these children within and outside education systems. Both parental and child consent was sought for the children and parents to take part in the research project (Hill, 2005). The children were considered as the primary participants with the parent interview being used primarily to clarify or respond to specific experiences elicited during the children's free-talk interviews, if necessary.

The narrative-informed case studies involved three to four separate interviews with each child, an interview with at least one parent, and field notes. The interviews were audio-recorded and transcribed, and from these, narrative stories were developed which were member checked for veracity and accuracy. The interviews were conducted in the participants' homes using a memory box where children collected items of interest to themselves prior to each interview, for sharing with the interviewer in order to elicit further details about their lived experiences (Martin \& Merrotsy, 2006).

Children were given the option of having a parent present during the interviews. This generated both affordances and limitations, as the presence of a parent assisted children with responding in the interview at times, but also impeded their responses on occasions when parents interrupted or corrected their children (Harrington, Foster, Rodger, \& Ashburner, 2013). In addressing parental 
influence during the interviews, the interviewer re-directed questions back to the child in order to gain their perspective and to check agreement or not with parental response (Preece \& Jordan, 2010).

The semi-structured interview questions were spread out over the three to four interviews, allowing 30-60 minutes for each interview. The initial interview involved an informal discussion surrounding the participant's memory box (from the pre-interview meeting where the collection box is given to the child), expectations of the interviewer and participants and focusing on building rapport and establishing trust. Questions such as Can you tell me a little about yourself? provided a gentle opening to the interview process, providing sufficient scope for the children to expand upon.

The first author entered the research context of the child's home as a participating adult who had the ability to assume the role of a compassionate, empathetic and sensitive adult (Birbeck \& Drummond, 2007). The relationship was founded and developed based on trust and mutual respect which enabled us "to uphold the ethical imperatives when working with children...this approach is entirely consistent with the social, intellectual and communication requirements of children if they are to participate in research” (Birbeck \& Drummond, 2007, p. 27).

\section{Child participants with a disability}

Prior to and during the interviews we had to develop "approaches and resources to address individual...needs" (Harrington et al., 2013, p. 2) of the participants. This was critical to ensure that the perspectives of the twice exceptional children were captured whilst maintaining trust and comfort for the participants. This involved an inclusive approach where the child's needs were addressed to ensure they were able to participate in the project, regardless of their disability and any communication needs. This was undertaken on an 'as-needs' individual basis (Harrington et al., 2013) and negotiated with the child and parent, to ensure appropriate and adequate approaches were used. As Harrington et al. (2013) suggest, we spent time getting to know the children to build rapport and increase comfort during the interviews, and this was primarily by engaging in activities that the children enjoyed. For some children, this meant the inclusion of pets during the interviews, along with with talking about their love and enjoyment of their hobbies. Also, for the most part during the interviews we sat on the floor and the children were able to sit how they felt comfortable, spreading their memory box items out. To support the participants' social and emotional needs during the interviews, parents were invited to share health professionals' reports and school records for their child prior to the interviews.

An integral part of the semi-structured, free-talk interviews, was the use of the memory box where children were given a box to keep items which they wished to 
share with the interviewer. The use of the memory box allowed the participants to include objects which were of significance to them for discussion during the interviews. The participants were able to 'show' these personal artefacts and through talking about these, we elicited further rich data to add to the authenticity of the narratives (Kim, 2016). In contrast to the other parts of the interviews, at these times the participant guided the discussion being led by their chosen objects, rather than the interviewer taking the lead. The use of the memory box allowed the children the opportunity to explain an aspect of their life that simply talking and questioning did not facilitate (Martin \& Merrotsy, 2006). This approach was flexible, allowing for the inductive nature of narrative research, providing further threads which could be woven into their narratives.

\section{Narrative approach}

A narrative approach acknowledges that stories of lived experiences are built through dialogue and experience telling (Kim, 2016) both as the phenomenon studied in our inquiry into the lived experiences of twice exceptional children, and as our methodology (Connelly \& Clandinin, 2006) . The language of the story is built up from dialogue with the participant who has constructed their narrative of self around their understanding of "the episodic and temporal qualities of lived experience ... human beings live out their lives in ways that can be understood and communicated narratively" (Cresswell, 2008, p. 157). In a narrative approach, the inquiry is related to the portrayal, reproduction, analysis and understanding of storied explanations of 'real' lived experiences. Narrative provides an interpretive framework as "a way of thinking about experiences... as a methodology [it] entails a view of the phenomenon. To use narrative inquiry methodology is to adopt a particular narrative view of experience as phenomena under study" (Connelly \& Clandinin, 2006, p. 477).

Understanding through a narrative informed case study approach is derived from "a willingness to comprehend meaning in context and to accept more than one 'truth'” (Munhall, 2001, p. 380). Ambiguity is a feature of narrative research and the investigator requires flexibility and tolerance in dealing with the unexpected and viewing these variations as opportunities rather than menaces (Munhall, 2001). Different threads need to be stitched together to form narrative constellations.

Clandinin and Connelly (2000) suggest that a narrative approach enables "a way of understanding experience... a collaboration between researcher and participants, over time... [where] an inquirer enters this matrix ... in the midst of living and telling, re-living and retelling, the stories of the experiences that make up people's lives, both individual and social... narrative inquiry is stories lived and told” (p. 20). 
The nature of narrative research means that a close bond was established between the researcher and participants, which assisted in establishing the direct applicability of the research (Kim, 2016). Through personal experience stories, and with the support of the memory boxes, the participant's personal narratives of twice exceptionality were explored. The personal experiences stories are both individual and personal, (their experiences), and shared, social experiences where individuals interact with others (Clandinin \& Connelly, 2000) which further emphasised the research focus of learning from children who are twice exceptional.

The field texts were made accessible and presented as narrative story constellations (following Clandinin \& Connelly, 1996; Craig, 2007). This approach, following from Craig's work and Clandinin and Connelly’s work, has been adapted to include the paired narratives of Children's Stories/Stories of Children. This approach is further expanded and explained under the story constellations section, later in this chapter. This approach revealed heuristic narratives about the lived experiences of twice exceptional children, at times coconstructed with their parents, leading to a deeper understanding of what the educational and daily lives are like for children identifying as twice exceptional. The story constellations approach enabled us to analyse and re-story the children's and parents' interviews. This produced rich, in-depth stories with inimitable permutations about narratives of lived experiences, recounted at specific points of time in the children's lives, stories lived and told (Clandinin \& Connelly, 2000).

Polkinghorne (2007) distinguishes between 'stories' as fictional portrayals and narrative 'stories' as being the "fundamental scheme for linking individual human actions and events into interrelated aspects of an understandable composite” (p. 13). Hence, narrative refers "to both the process and the results" (p. 13) of narrative research. The narrative method enables the formulation of reasonable analysis and interpretation of findings and the building of a worthy line of reasoning (Bassey, 1999).

Therefore, the resulting case study narratives are "descriptive, inductive and ultimately heuristic - [seeking] to 'illuminate' the readers' understanding of [the] issue[s]" (Cresswell, 2008, p. 33). In essence narrative research is an exploration and investigation of current real-world phenomena through the in-depth analysis of a narrow series of events, interactions and/or circumstances, and how these interconnect (Yin, 2009) in the lives of twice exceptional children.

\section{The Interview protocol}

The interview protocol involved specific information relating to each child, and it was flexible, incorporating any disability adjustments necessary (e.g., breaks, moving around, playing with objects/toys during the interviews). The interview program included a pre-interview which took place at the initial meeting with each 
child and their parents. The aims of the pre-interview were to familiarise the children with data collection expectations and to answer any queries that they had relating to the research. During this meeting each child was provided with their memory box which they kept for storing their items to share with me during the interview process. Most of the participants already had items ready to show me at the first pre-interview, despite not already having the box.

The parent interviews were characterised by a sense of urgency and this appeared to come from the need and desire to have other people know about their stories (Chase, 2003). The stories represented a catharsis of sorts for both the children and their parents, presenting "the cathartic advantageousness of exchanging memories or lived experience” (Duffy, 2011, p. 89). This process is examined further after the presentation of Ashley's story constellation.

\section{The Interview schedule}

The interviews were guided by Seidman's (2006)three-phase interview process. In this approach, Seidman suggests that a person's behaviour becomes more comprehensible and meaningful when positioned in their life-context and in the lives of those around that individual. This contextual positioning assisted in developing our understanding though the interview process, of the daily lived experiences of twice exceptional children and the meaning these children made of their experiences.

Seidman (2006) suggests that the first phase interview (focused life history) (table 1) should place the individuals' experiences in context. In the first interview, the participants were asked about their experiences relating to their lived experiences up to the present point in time-their "focused life history" (p. 21). The second phase (the details of experience), further focused on concrete details and examined twice exceptional children's lived experiences within a context (Seidman, 2006). The third phase (reflection on the meaning) was where the participants were asked to reflect on the meaning of their experiences, and to make intellectual and emotional connections with their experiences. This increasingly focused third phase was where previous data was amalgamated with other contextual information, to reach crucial meanings that the participants had of their lived experiences (Seidman, 2006). The three-phase process was spread over three to four interviews with the child participants, ensuring, as much as possible, that each stage was adequately addressed prior to moving on to the essential final stage. This process aided in initial analysis of these data from each interview stage, to inform subsequent interviews. A final interview with parents helped in clarifying and expanding on information and ideas garnered from the children. The child's verbal permission was sought for this after their final interview and prior to the parent interview, which immediately followed the child's last interview session. 
Seidman (2006) recommends asking participants to "reconstruct rather than to remember" (p. 88) experiences, and that researchers should focus on concrete details that constitute particular experiences. In essence, this required asking questions such as “what happened?”, rather than “do you remember ...?” (p. 88). With recalling experiences being based partly on memory and partly on what participants see as being important about their past experiences, "in a sense all recall is reconstruction...in interviewing it is better to go for that reconstruction as directly as possible" (p. 88).

We did not take field notes during the interview as we found this could be offputting as the children may be wondering what I was writing down. Once we left the interview location we spent some time writing our field notes and observations from the interviews.

\begin{tabular}{|c|c|c|}
\hline Interview & Interview Focus & Task \\
\hline $\begin{array}{l}\text { Pre-intervie } \\
\text { meeting }\end{array}$ & $\begin{array}{l}\text { Getting to know each } \\
\text { other; establishing } \\
\text { rapport; building } \\
\text { trust; }\end{array}$ & $\begin{array}{l}\text { Introduce myself, give child } \\
\text { memory box, interview } \\
\text { structure, establish } \\
\text { rapport/trust; setting -child's } \\
\text { home -where they feel } \\
\text { comfortable sitting). }\end{array}$ \\
\hline $\begin{array}{l}\text { First } \\
\text { Interview }\end{array}$ & $\begin{array}{l}\text { Questions 1-4- How } \\
\text { Q’s: Tell about self; } \\
\text { Experiences in } \\
\text { context; }\end{array}$ & $\begin{array}{l}\text { Establish rapport/trust, } \\
\text { memory box -setting (floor } \\
\text { etc. child is comfortable). }\end{array}$ \\
\hline $\begin{array}{l}\text { Second } \\
\text { Interview }\end{array}$ & $\begin{array}{l}\text { Questions 5-11 - Do } \\
\text { Q’s: Experiences in } \\
\text { context \& concrete } \\
\text { details about lived }\end{array}$ & $\begin{array}{l}\text { Continue to build } \\
\text { rapport/trust; memory box, } \\
\text { interview setting (floor etc. } \\
\text { where child is comfortable). }\end{array}$ \\
\hline $\begin{array}{l}\text { Third } \\
\text { Interview }\end{array}$ & $\begin{array}{l}\text { Questions 12-19- } \\
\text { Concrete details about } \\
\text { lived experiences \& } \\
\text { Reflect on meaning of } \\
\text { experiences (making } \\
\text { intellectual/emotional } \\
\text { connections); }\end{array}$ & $\begin{array}{l}\text { Continue to build } \\
\text { rapport/trust memory box, - } \\
\text { interview setting (floor etc. } \\
\text { where child is comfortable). }\end{array}$ \\
\hline $\begin{array}{l}\text { Fourth } \\
\text { Interview }\end{array}$ & $\begin{array}{l}\text { Questions 20-26 - } \\
\text { Reflect on } \\
\text { experiences (making } \\
\text { intellectual/emotional } \\
\text { connections); Future; }\end{array}$ & $\begin{array}{l}\text { Continue to build } \\
\text { rapport/trust - interview } \\
\text { setting (floor etc. child is } \\
\text { comfortable). }\end{array}$ \\
\hline
\end{tabular}




\begin{tabular}{lll}
\hline $\begin{array}{l}\text { Parents' } \\
\text { Interview }\end{array}$ & $\begin{array}{l}\text { Reflect on } \\
\text { experiences - co- } \\
\text { construction of } \\
\text { narrative). }\end{array}$ & $\begin{array}{l}\text { Questions that have arisen } \\
\text { during the interview phase } \\
\text { and from any documentation. }\end{array}$ \\
\hline
\end{tabular}

Table 1: Interview guiding schedule linked to interview questions following Seidman (2006)

\section{Narrative Analysis}

During the interview phase of the study there was ongoing preliminary analysis of each interview to inform subsequent interviews and to guide the three-phase process. Immediately after each interview the first author wrote field note précis, summarising the interview content and noting any features for further attention. The interviews were transcribed verbatim, including utterances, pauses, silences, false starts and other vocalisations, including laughter, and the transcript was then reviewed against the audio recordings for accuracy, and verified where applicable. This preliminary exploratory analysis gave a general sense of the data, where initial ideas were noted, and subsequent interview questions were organised (Kim, 2016). The transcription of the spoken discourse became "like photographing reality, ... an interpretive practice... by displaying text in particular ways, [providing] grounds for [my] arguments, just like a photographer guides the viewer's eye with lenses and by cropping images” (Kohler Riessman, 2008, p. 13). The field notes and memos gave guidance to our ideas, thoughts and feelings, used as an aide-mémoire technique.

After the initial review of the verbatim transcripts, these were again reviewed alongside the audio-recordings. During this re-reading and re-listening, superfluous talk was removed (or snipped) from the transcript (e.g., about the weather and talk deemed repetitive or irrelevant). This process was extensive and led to a first draft of each child's narrative. The first-draft narratives emerged from the transcripts after we began to snip away "at the flow of talk". This involved "decisions about form, ordering, style of presentation, and how the fragments of lives that have been given in the interviews [would] be housed” (Riessman, 1993, p. 13). These draft narratives were sent to participants' parents for member checking in conjunction with their child.

Bruner (cited in Polkinghorne, 1995) remarks that "people do not deal with the world event by event or with text sentence by sentence [rather] they frame events and sentences in larger structures” (p. 15). It is through Polkinghorne’s (1995) narrative structure of plot that people comprehend and define the relationship between events and life choices throughout their lived experiences, and it makes 
sense to use this method to grasp these together as one cohesive story through narrative configuration. With this in mind, we were interested in telling stories of lived experience, rather than reporting a series of sequenced, themed events from passages of transcribed text (Patterson, 2013). We sought to evaluate passages of text - chunks of data — which disclosed how the participants felt about their experience "and mediated the point of [their] story" (Patterson, 2013, p. 36).This was undertaken so we remained close to the nuanced features of these transcribed narratives. The goal was personalised narratives of lived experience rather than “an event-centric understanding of personal narration” (Patterson, 2013, p. 36). Therefore, a hands-on approach for the analysis ensued where we reviewed narrative drafts, which were re-read, further edited and amended, taking into account the participants' feedback. This editing re-shaped the narratives, "turning [them] into a hybrid document” (Riessman, 1993, p. 13) where the participants' voices were central (Gubrium \& Holstein, 2002). This re-reading of the hybridised-narratives took place several times, where the first author immersed herself in the details, endeavouring "to get a sense of the interview as a whole before [further] breaking” (Agar, 1980, p. 103) them into segments and threads of experiences.

After initial reduction of each of the narratives, Polkinghorne's (1995, 2007) narrative analysis was used as an emplotment process in analysing the field texts. The process involved "happenings [being] drawn together and integrated into a temporally organised whole” (Polkinghorne, 1995, p. 5), the outcome of which were story constellations of lived experiences. This was undertaken by using what Polkinghorne described as using "a thematic thread to lay out happenings as parts of an unfolding movement that culminates in an outcome” (p. 5), the outcome of which was the stories of lived experience - the story constellations. This narrative analysis involved the development and discovery a plot that demonstrated links amongst data elements as segments of "an unfolding temporal development culminating in a denouement” (Polkinghorne, 1995, p. 15). This denouement (conclusion) formed the basis for each of the story constellations, drawing together the narrative threads across the children's experiences. During the latter stages of data analysis, we used the configuration process of emplotment, where plotlines began to take on narrative meaning and started to develop an understanding of the plotlines' influence on particular outcomes and experiences (Polkinghorne, 1995). Emplotment was used on the hand-coded transcripts, and then further developed on the initial re-storied narratives to draw out the essence of these. We organised and constructed the elements of the textual data by emplotment, into the individual story constellations. This assisted in unifying and providing meaning to the textual data as contributing to my objective and purpose (Polkinghorne, 1995) of exploring the lived experience of these twice exceptional children.This narrative analysis involved our developing and discovering a plot that demonstrated links amongst data elements as segments of "an unfolding temporal development culminating in a denouement” (p. 15). This 'denouement' 
formed the basis for the 'story constellations', drawing together the narrative threads.

\section{Story Constellations Approach to Analysis}

Clandinin and Connelly (1996) discuss 'working landscapes' of teachers' knowledge and relationships with this landscape to policies, theories and other educators. They talk about landscapes outside classrooms where "knowledge is funnelled into the school system for the purpose of altering teachers' and children's' classroom lives” (p. 25). This landscape of knowledge can be said to include the lives and experiences of children, both within and outside classrooms and educational institutions. This filteringoccurs in not just policies and theories, but in the lived experiences of children (students), particularly those with differing experiences and backgrounds of diversity; in our case children identified as twice exceptional. Also included are the storied experiences of their parents' in the children's multi-vocal narratives (Czarniawska, 2002). In this multi-vocality of children and parents, many narratives are presented. Our role as researcher is not to say one is more 'truth' than any other, but to enable readers to comprehend the similarities and differences in and between the stories.

By using Clandinin and Connelly's metaphor of landscape, the children's stories would seem to come down from the hills, filtering through the landscape like streams through the rocks and vegetation, heading to the fresh water springs of the school landscape, and distributing their experiences for educators and policy makers to learn from. Producing interpretive accounts as narratives (Clandinin, 2013), which tell and re-tell of lives lived, of lives being lived and of re-living (Clandinin \& Connelly, 1996; Riessman, 2008); the narratives operate as a process of interpretation and re-interpretation of experiences.

Clandinin and Connelly present their story sets of teachers' stories as unfolding in a landscape of paired narratives. These narrative pairs are teacher storiesstories of teachers; school stories_-stories of schools. This relates to Dewey's (1997) concept of education, experience and life being indivisibly interwoven with Dewey suggesting that the study of life is the study of experience.

In Craig's (2007) story constellations approach, teacher experiences are brought to the fore, endeavouring to situate teachers' knowledge in the many environments where it is formed. Craig suggests two further "companion sets of stories to Clandinin and Connelly's matrix: stories of community-community stories, and stories of reform-reform stories” (p. 177). Craig suggests that these additional pairs allow for further "perspectives and offer a more panoramic view of the complex forces influencing school milieus and shaping the horizons of what becomes available for teachers to know” (p. 177). 
Through this approach Craig seeks to uncover "experiential stories about school-based educators working in relationship" (p. 175). Our aims in this study are similar, in that we sought to uncover "experiential stories," and examine the "complex forces influencing school milieus" and societal milieus. However, the stories we wished to unearth were those of the students, the children in the teachers' landscapes and beyond. Ultimately, the lived experiences of twice exceptional children, both inside and outside traditional educational landscapes, including their home lives beyond the schools' horizons.

The story constellations approach was therefore adopted to support the relationships in and between the children's narratives, and as a way of presenting the multi-vocal narratives. We have added to Clandinin and Connelly's narrative pairs, and augmented Craig's two other companion story sets with children's stories—stories of children. The augmented story constellations approach provided the opportunity to draw together narrative thread and plot lines in the denouement process described earlier.

\section{Re-Storying of the Research Texts}

Through story constellations, the narratives we composed and re-storied were able to remain close to the data, and enabled the voices of the children to be heard (Gubrium \& Holstein, 2002). Through the parental narratives, which enhanced and amplified those of the children, a multi-vocal story was created. Through restorying plotlines and segments of narratives, taken directly from the transcribed interviews, they were first decontextualized somewhat, "but in return [this] also recontextualised them as engrossing narratives (Czarniawska, 2002, p. 744). By recontextualising the narratives they were returned to the context, through which they were told, as recollections, as parts of stories, as lives being lived and as 'messy' stories. Clandinin and Connelly (2000) speak of the ever present context in narratives which is inclusive of "temporal context, spatial context, and the context of other people” (p. 32). We endeavoured to present each child's contexts through their narrative accounts as a way of demonstrating the holistic child, contextualised by their experiences and the places where they lived, re-lived and re-told those experiences. However, all these analytical processes were dependent on thorough and thoughtful interview data. In the following section we present a section of one of the case narratives. We then return to a discussion of the interview features and practices that facilitated the data generation required for development of the narratives of these twice exceptional students. 


\section{Story Constellations}

Here we set out part of one of the participant's story constellations. Although we would like to present a fuller and more comprehensive story, for the purposes of this chapter we have only included a limited version. Nevertheless, through this approach the children's lived experiences can be situated in the contexts of where those experiences are formed.

\section{Ashley's Story Constellation}

\section{Children's Story/Story of Children}

(Note: The following is re-storied and written in first person by the first author).

Through Ashley's narrative extract, we weave the interview process and our analysis of the field texts to produce our initial visual story constellation based round the emerging themes.

Ashley is 16 years and two months old. She lives with her family in a middleclass suburb in far north Queensland, Australia. Their home is low-set in a quiet, leafy cul-de-sac. At the time of my visits, spread over eight weeks in late summer and early autumn, I was privileged to share Ashley's unique experiences and her family's experiences; those of having a sibling with profound intellectual disability. The following narrative is a snapshot of those lived experiences.

\section{The Interviews}

Ashley and I had spoken on the telephone prior to my first visit. I'd also spent some time in email correspondence with Susanna, Ashley's mum, and we'd talked on the telephone too. We'd devoted some time to discussing Ashley's disabilities, particularly anxiety, and abilities, namely in the area of Visual Arts and music. The primary reason for our communication had been both Ashley's and Susanna's interest in taking part in my research study.

Ashley's disabilities included a diagnosis of Pervasive Developmental Disorder Not Otherwise Specified, (on the autism spectrum), Semantic Pragmatic Language Disorder and anxiety. Prior to our interview, Susanna, Ashley's mum had told me via email that; 
Ashley was quite insistent that she did not want to be identified as disabled anymore. So two months ago we went back to [care centre] to be 'undiagnosed' [for Pervasive Developmental Disorder Not Otherwise Specified, Semantic Pragmatic Language Disorder].

In one of her first emails, Susanna wrote;

Ashley is quite gifted though she is not a savant. She plays the piano quite well and can 'jam' and make up compositions on the spot. She is very good at art and loves it. Both of these subjects she is going to be studying in her final two years of high school. English, she loves and even got an A+ for her Romeo and Juliet essay, which she had deliberately set out to do. She is also doing physics, chemistry and maths. She has trouble with the algebra side of maths.

In the same email, Susanna told me of her eldest daughter, Sarah, 18 years old, who has a profound disability, affecting her cognitively and physically. Susanna and her husband, Lesley, were placed in the principal position of having two children, both with disabilities, but profoundly different needs, particularly related to care. Sarah needed round the clock support and regularly went to respite care. On the other hand, Ashley needed interventions, particularly when she was younger, and specialist care, but with the added need of creative stimulation to cater for her giftedness.

On my first visit to their home, I heard voices from within as I approached and Susanna greeted me at the front door with a happy smile, ushering me into the coolness of their home. Ashley appeared from the darkness of the kitchen beyond the family room where Susanna and I stood. A young woman slept on the patterned sofa in one corner of the room. I presumed this was Sarah. Two cats were fast asleep at the other end of the sofa. All three looked cosy and relaxed, not stirring as I entered their home.

As we settled back in our chairs to begin our chat, one of the cats awakened, and seeing a visitor came over to check me out. I reached down to allow the cat to sniff my hand, "Oh hello gorgeous." I exclaimed as the long-haired grey cat brushed against my hand. Ashley introduced her pets "This is Tiny Lass [pseudonym]. We have two cats, this is Tiny Lass and the other one over there, next to Sarah, is Tex [pseudonym]. By acknowledging and talking with Ashley's pet as I do with my own, I had unintentionally begun to build rapport with Ashley. Even though we were talking in a place where Ashley felt comfortable, in the family room of her own home, she was still meeting me as a stranger; despite our brief telephone chat we did not know each other. I was aware of Ashley's autism diagnosis and anxiety from the information Susanna supplied. The presence of the cats gave me the opportunity to ease both Ashley's and my own social anxiety and act as a buffer to any difficult interview beginnings. It is acknowledged in the literature (O’Haire, McKenzie, Beck, \& Slaughter, 2015) that children with autism experience significant social anxiety, and as Ashley talked I learnt more of this.

As Ashley scoops the cats up onto her lap and caresses its belly, the cat begins to purr, Ashley opens up to tell me about her disabilities and how they may have affected her; I can tell how much of an annoying child I was. I would sort of call 
out when it was inappropriate in class, like yell stuff out, and it would just be sort like that's just rude, you don't need to speak right now. I wasn't the best with my social skills during Primary School; like I could not cope with females, too complex. My friends were all guys, because it was easy, you just had to punch them on the shoulder and they got the message.

Sometimes it's a bit difficult getting sentences out, I've always found, to have a one on one conversation with a person, where I have to look at them for a very long time, gets stressful and I will cut off. As Ashley talks she appears comfortable, looking at me as we talk; it is more of a conversation between two people than an interview situation. Her body language shows she feels at ease, sitting back in the chair with the grey cat curled in her lap, her body turned slightly towards me as she talks.

Sometimes I would just shift sentences back to front, or words. Let me think of one, say 'treen grutle', I would say something like that, when I would mean to say, 'green turtle'. I would swap the front...letters and stuff around. But sometimes I do it in front of people and they just look at me, I'm like, 'Did I just say something funny?' I don't realise it at all. Not until someone goes, 'You just said this', and I go, 'Oh! What?' It's like I've swapped a whole sentence around, I will replay stuff myself... I'll probably be thinking about something else at the time or doing something and it will come out.

Having the cat on her lap seems to enable Ashley to be at ease with me as we talk my interest in the cats also helped build rapport. Ashley invites me to stroke the cat as it now sleeps peacefully on her lap, a significant sign that she is open to sharing her pets with me and leading further to sharing her experiences. The cat is a living part of her 'memory box' as we talk, emphasising the ties Ashley has with her pets.

\section{Special Education}

As we stroke the cat, we talk about how Ashley felt being in the special education program at school as a result of her disability diagnosis; Well I was like 'You don't need to treat me like this'. It just makes me very angry to have people decide who I am... because I'm not that. You don't get the right to choose. I'm sorry but having a personality and being a little bit different to everyone else, I don't think is acceptable to classify me as having a disorder, saying that I'm different and weird because of it, I don't think that's right. I think we're getting to the stage where everyone's just going to be diagnosed and no one's going to be normal. That's so the end of it, because you're going to get diagnosed for having a personality. You've got it or not! My counsellor has this on the wall, 'Everyone's normal until you get to know them.'... It's just more like you start off as a genius, we're seen as amazing but as you get older you become normal. And it's quite correct actually, because as you get older you just become normal. Oh here's the other one. Ashley says as her other cat comes to see what we are doing. 
The cat comes over to my bag and sniffs, curiosity getting the better of him: he sticks his head in. We pause to pay attention to the cat, chatting about his antics and laughing as he tries to climb into my bag. Susanna comes in, drawn most likely by our laughter at the cat's antics.

Susanna tells me; One of the reasons why I didn't want Ashley undiagnosed, was because I was very concerned that the fact that we're now going in to year 11 and 12, when it really mattered, maybe this was the time we might have a meltdown, and anxiety. Ashley and Susanna discuss the reasons why they both feel the opposite, as I listen intently, both sides sound reasonable to me, Ashley doesn't feel the label helps her and Susanna would like the educational and emotional support the label brings for Ashley, especially in the final school exams and assignments coming up in the next year. They seem to have to agree to disagree.

\section{Anxiety and Agoraphobia}

Susanna tells me that; Ashley actually suffers very badly from agoraphobia and it was about a year ago that I called her aside and had a talk with her. She wouldn't go out with any friends or anything like that; she would only go out with church ladies who were in their fifties because she trusted them. It all really started I think from that big storm that we got caught in, you know the big one that happened, it's called the [name of storm]. How I remember the supercell that it was equivalent to a hurricane 2 or cyclone 2. We got caught right in the middle when we were driving. It was terrifying I have to say, it was real terrifying. Ashley was terrified of storms after that.

She just wanted to be home and so I said to her, 'This is not right, we need to go and see counsellor.' Ashley's really improved from it. So a lot of that going out came from anxiety, so I think Ashley is quite an anxious child. We've just been [to the specialist centre] again and she's been totally undiagnosed with autism but with the agoraphobia the counselling has really helped. I just got to let you know, sorry to be barging in. I thought you needed to know." Ashley's sitting quietly, occasionally glancing at her mum and nodding in agreement as she talks. I get the feeling Ashley wanted to tell me about the agoraphobia but perhaps didn't know how to broach the subject.

I ask Ashley how she went with getting through those feelings of not wanting to go out and being anxious;

The counselling was really good. Talking about it, it was the thing of coming up with plans of I'm able to get out of situations if I want to, I can have plans in place for what I can do. They originally actually put me on drugs to help along with the therapy. I tell you one thing, I did not like those! They turned me ADHD. I could not sit still, it was the most vile feeling ever, I felt sorry for those who have $A D H D$, because it was just terrible. I felt always on edge, and I hated it, I couldn't 
stand it. I was on it for a couple of weeks, I was like, 'I can't do this anymore!' I don't see the need to have drugs. It's annoying side effects getting that really, jittery stuff from it, obviously I was just possibly unlucky. It was like I didn't want to go out. Even now, sometimes I'll get quite defensive...

I would feel really nervous, sort of sick in the stomach, stuff like that, and I'd always be on edge and I would always be watching the sky. I don't have issues now with storms, I still wouldn't want to go out in car, that's just common sense! But I don't get that whole jittery feeling when ones around, like I would get that thing sort of sick feeling I would get when going out, when I was in the house when there was a storm, and I would normally go grab the cat, try and occupy myself with something else... but I don't really have those issues anymore... thankfully. Ashley sheds some light on the importance of her pet cats as part of her extended family as she cuddles up with them both when she feels anxious and stressed. The cats appear to prompt positive emotions for Ashley as O'Hare et al. (2015) found in their study with children who had autism, meaning Ashley's pets may function as effective social buffers and confidants for her (Melson, 2001).

I think I'm a sort of person that needs to be told, 'It's okay to be [anxious] like this and that there's ways that you can get around it and it's not wrong to feel this.' I just need to be able to have an action plan, because you can't let it stop you from going and doing stuff. Yeah, because I'm a sort of person who's like, 'God won't help you if you won't help yourself.' I find it irritating when people sit in the corner and go, 'There's something wrong with me,' and stuff like that. You can go do something about it, just don't sit there and complain, go do something! If you've got problems, try and solve it yourself. Like obviously I've had issues since I was young with my social behaviour and stuff, and I was still bad in grade 7 and 8. In grade 9 I felt that was a very big year of change for me socially, like I stopped associating with people who associated with others that just upset me. I thought I became much more responsible that year and much more mature and I was making more friends on my own with much more creative artsy friends. I had to do so much to change myself, I've tried really hard to get to where I am and mum's helped a lot in therapy. Ashley trails off as one of the cats rolls over to have her stomach rubbed, and cat hair swirls up into the air as Ashley cradles the cat lovingly on her lap.

\section{Analysis of Ashley's Story Constellation}

Through Ashley's story constellation of self-identity, the importance of her wanting to be 'undiagnosed' emerged quite strongly, she unintentionally challenged the labelling of her as a person identified as twice exceptional—she did not want to be seen as someone with a disability anymore. We had inadvertently called, or 'hailed' (to use Althusser, 2001, favoured verb) Ashley, to be or become, what being twice exceptional involved—identifying as a person with 
giftedness and with disability. She no longer wanted to take up this identity-the disability aspect at least, which had been allocated to her by a system which had no alternative if it was to intervene and support her education and development. Ashley at 16 years old, had come to see herself differently. As far as she was concerned her circumstances had changed, she now found having a disability label to be contentious, as a source of discomfort and dislike.

She was in the process of change, not just into a young woman, but in recognising and deciding to have a say in how she wanted to be perceived by others. This is what Clandinin (2013) refers to as 'relational' in narrative inquiry; the relational between Ashley and her world, Ashley and her lived experience which had shaped and brought her to this point in time.

Ashley's evolving knowledge about her young adult self, her past experiences around disability and her disability status, had led her to her current vantage point. Thus, her knowledge about herself was "entwined with [her] identity” (Clandinin, 2013, p. 53). Clandinin suggests that through thinking narratively about who we are and where we fit in "speaks to the nexus of a person's personal practical knowledge, and the landscapes, past and present, on which a person lives... a concept of stories to live by allows us to speak of the stories that each of us lives out and tells of who we are, and are becoming... this highlights the multiplicity of each of our lives - lives lived out and told around multiple plotlines” (p. 53). Her present vantage point is clearly influenced by a multiplicity of different factors.

Ashley uncovered that perceptions of her by significant others; parents, friends, peers and teachers, were of importance: they mattered to her. Because of this she did not want those people to see her as incapable in any sense, as she perceived a label of disability showed her to be. She felt those narratives of disability were fixed to her by significant others (Clandinin, 2013). By having others story her in these ways was immensely disturbing to her.

Ashley was seeking to construct "preferred narratives" (Kohler Riessman, 2008, p. 7) about herself. Riessman suggests that our propensity with identity is "no longer viewed and given as 'natural', individuals must now construct who they are and how they want to be known...in postmodern times, identities can be assembled and disassembled, accepted and contested.” (p. 7).

\section{The Interview Process}

Developing the interview protocol began before the first meeting with the gathering of background information from Ashley's mother, including specialist reports and assessments, and school records (table 2). This information and the email and telephone conversations with Susanna assisted in providing me with a clearer indication of any special consideration needs that Ashley might have during the interviews, which we needed to allow for. This was vital for the 
interview protocol, enabling me to adapt the interview process appropriately (Wilson \& Powell, 2001). From the background information we established that Ashley had a form of ASD which may have affected her communication, her receptive language. This meant we could approach the pre and first interviews with this in mind, to be flexible in the way we spoke and posed questions, aware of the possibility that Ashley may have had some difficulty in comprehending and processing verbal language. During the telephone conversation I had with Ashley prior to our first meeting, I became aware that her receptive language was very acute; this was confirmed during our first face-to-face meeting. With this in mind we were able to proceed with the interviews, knowing that at times there might be the need to repeat or change questions as needed. Ashley also had a diagnosis of anxiety and agoraphobia which may have affected her during the interviews, even though she was in her own home, a place where she felt comfortable, she was still being exposed to myself as a stranger. This further emphasised the need to carefully build rapport and put Ashley at ease with me. Susanna shared with me some insights into Ashley's interests, which included music and art. Being an artist and an art teacher, this was a clear door into Ashley's world.

\section{Type of information sought}

Name of child and pseudonym choice

Parents' names

Address

Date of birth/age

Disability assessment/diagnosis - any impact these might have on the interview process

Gifted assessment - any impact this might have on the interview process Type of schooling

School reports

Out of school interests/hobbies and achievements

Table 2: Information checklist prior to the interview

\section{Preparing for the First Interview}

Working from the background information and being aware that Ashley had a diagnosis of ASD and anxiety, meant I was able to consider elements of the interview protocol well before our first face-to-face meeting for the pre-interview. I considered what I would wear to the interviews; where in the home the interviews were to be conducted; the initial greeting and how I would need to place Ashley at ease straight away; my use of appropriate language-the use of 
my voice - tone, inflection, clarity and so forth; the use of the memory box; and ending the interviews.

\section{Dressing for the Occasion}

Being a teacher I have a professional way of dressing for teaching situations, whereas for the interviews I wanted to present myself casually, in a less formal way so that Ashley was not intimidated by my formal attire. I therefore, placed some consideration to my dress prior to each interview, dressing smartly, yet casually. Being aware of Ashley's ASD also made me conscious of not wearing clothing which was overly patterned or colourful, which might be distracting during the interviews. I did wear a small charm necklace to the pre and first interview session, which after my self-reflection from the first interview, had provided Ashley with a focal point on me, rather than having to keep constant eye contact during our chat. This appeared to allow Ashley to focus on what she wanted to say rather than being distracted by remembering to keep eye contact.

\section{The Environmental Context}

Previous interview methods for children with disability included structured diagnostic and screening interviews usually undertaken in clinical settings. By going to Ashley's home, a place where she felt comfortable, surrounded by the familiarity of her home and her extended family of two cats, Ashley was able to be herself. Our 'free-talk' interviews provided a clear focus through flexibility and responsiveness, to Ashley and her environment. The time of day was also taken into consideration when arranging the interviews with Ashley and Susanna to ensure that they were in the mid-morning but not too early, so that Ashley was well-rested and cognitively prepared for the sessions; alternatively early afternoon, following lunch. The interviews took place mid-week of the two week Easter school break; subsequent interviews were arranged on Saturdays during the day, so as not to interfere with Ashley's school week, homework and social life. This arrangement aimed to ensure that Ashley was not too tired from a day's work at school, and the process was not perceived as a nuisance or interfering too much with Ashley's other commitments.

\section{Initial Greetings}

The initial greeting was important at each of the four interviews, but none more so than for our first face-to-face meeting. First impressions do count and I needed to present a positive influence (Zwiers \& Morrissette, 1999) on Ashley and her parents, whom I had not met previously. I needed to smile, looking at Ashley as 
Susanna introduced us, presenting my open, honest and friendly demeanour from the beginning.

\section{The Pre-Interview}

The purpose of the pre-interview with Ashley was to begin to build rapport and trust, an ice-breaking conversation. Barker (1990) underlined the importance of building rapport, not just initially but ongoing during the interview and subsequent interviews. He defined rapport as a condition of consideration, empathy, accord, and consistency, an understanding and considerate relationship personified by warmth towards each other (Barker, 1990).

Initially we talked in general, making chitchat about my trip up to her home, which gave me the opportunity to gauge how Ashley felt in chatting with me. I termed the interviews 'chats' rather than 'interviews', when I needed to use the phrase, to make the conversations sound less formal. This pre-interview phase allowed me to use open-ended questions to build rapport and enable Ashley to become familiar with my child-centred approach to the interviews, where she was free to talk as much as she wanted (Wilson \& Powell, 2001), so that she was able to see my genuine interest in her experiences as a twice exceptional person. During this time I also told Ashley more about my study, why I was doing it and some personal information about myself, such as children, pets, being an artist and art teacher, and where I lived. As the nature of communication is a reciprocal process, I encouraged Ashley to ask questions about the study and myself, and my artwork. After all, I was asking her to disclose information to me, so I reciprocated by sharing some of my information through self-disclosure (Zwiers \& Morrissette, 1999). One of the main subjects we began to talk about in this initial rapport building phase, was Ashley's two cats, who were asleep on the couch when I arrived.

Having two pets of my own, a cat and a dog, also helped to build rapport with Ashley during the pre-interview and subsequent interviews, as I could relate to her cat stories and they became a 'bridge' to fill-in when the conversation subsided. This supports findings in the literature, particular for children with ASD, that having a pet present increases social interaction when compared to having no animal present (O’Haire et al., 2015). Ashley would often ask me if my cat had similar behaviour as we exchanged stories about our cat's antics. I knew how to interact with her pet cats, and having that understanding gave me the ability to talk from a position of knowledge with her about her cats.

During the pre-interview I prepared Ashley for what was involved in the interviews; letting her know it was okay to choose not to answer any questions or not to talk about anything that she did not want to, and that she did not have to give a reason. Additionally, I let her know that she could stop at any time also 
without having to provide a reason to me. I informed Ashley that I was not there to be judgemental and that she was free to choose what she wished to share about her experiences and what she did not wish to share.

\section{Language and Tone of Voice}

The dynamic, child-centred interview protocol that we developed and implemented allowed for the reciprocal process of interviewing Ashley, Ashley liked to talk, and I was good at listening, but when it came time for Ashley to have feedback from me, I was able to provide supportive gestures, in the form of nodding, and vocal sounds to show I was actively listening and taking in her sharing of experiences. This reciprocal process meant we influenced one another, by creating a discourse whereby I was inviting Ashley to share and explore her thoughts and experiences (Zwiers \& Morrissette, 1999), then as appropriate, I could clarify and explore her responses once the free-flow had subsided. During this time, Ashley would ask me questions, or ask for my experiences of certain events. It was important to share this information in a limited capacity only after Ashley had shared her experiences, so as not to directly influence what she was recounting. This developmental protocol with flexible, open-ended questions, was able to respond to new information from Ashley with further questions, and comments to gain a more thorough understanding of Ashley's lived experiences (Zwiers \& Morrissette, 1999).

\section{Memory Box}

The memory box served to bring into the conversation and to prompt memories from Ashley's lived experiences. The artefacts from her memory box, did not in themselves form part of the field texts, however, during the first and subsequent interviews, they provided "triggers" (Clandinin, 2013, p. 46) for telling her stories. The importance of Ashley's extended 'family' and support network she felt her pets provided her was reinforced with the cat collar which she included in her memory box items for the first interview. The collar was the first collar her cat had as a pet, on showing me this, Ashley expanded on the importance of her cats in teaching her responsibility: I included that because that was just more representing how, when I first got her, the responsibility I started to learn from having a cat. That it's something to look after and the relationship because, oh a cat they're such a stress relief, because you just pat and they purr and they make you feel happy. She's like best thing in your life, I felt so happy.

\section{Ending the Interviews}


Our chats had been extended beyond the set time on many occasions. We scheduled 30-45 minutes for each interview, despite my protestations that I was taking up their time; both Ashley and her parents welcomed me to stay well beyond the allocated time frames. On one occasion we chatted for over two hours, Ashley occasionally stepping out of the room to collect another artefact to share with me, Susanna joining us to share her thoughts; me sipping my water and Ashley her coffee, as I listened intently, intermittently briefly sharing an anecdote from my experiences. They treated me like a special, important visitor, but also as a kind of collaborator, ally and cherished friend. At the end of each of our interview chats, Ashley and Susanna would accompany me to the door, chatting further as we moved from the living room to the front door, then they would stand on the driveway, we would still be talking, eventually I would make my final goodbye in their quiet cul-de-sac as they waved their last farewell.

Having spent many hours with Ashley and her family over the course of the interviews, (which took two months), to eventually have to close off the interview chats was quite difficult. We had become quite attached and almost formed a friendship of sorts based on our mutual interests. Ashley had shared her confidences with me, as had her parents during their interview; it was difficult for me at least, to accept the reality that I was not going to be visiting them anymore. The relational nature of narrative research (Clandinin \& Connelly, 2000) meant we had both undergone a transformative process through the character of our dynamic relationship. However, as Mahoney (2007) states "Blurring the lines between our friendship (private intimate relationship) and our research collaboration (public fieldwork relationship) was a balancing act” (p. 589) throughout the interview process.

The process of exiting the field was always going to be difficult following our relational rapport, according to Michailova et al. (2014) "is a contested terrain serving as the loci of multiple and multivalent emotions, and it is because of this that it can be powerful for learning and unlearning (p. 149). This was the start of a new part of my journey to continue to analyse and co-construct Ashley's narrative. After transcribing and re-storying Ashley's story constellation, I sent it to her and Susanna for member checking and feedback. This to-ing and fro-ing process meant that although I had left the field, I was still in email contact. Susanna would from time to time, share Ashley's recent experiences and achievements with me. I knew this would slowly fade over time, and it provided a slow and comfortable exit for me from their lives and the stories Ashley and her parents had shared with me, stories lived and told, re-lived and retold (Connelly \& Clandinin, 1990).

\section{Conclusion}

The flexible and dynamic interview approach facilitated Ashley's sharing of her lived experiences of twice exceptionality. Experiences centring on self- 
identity, seeing herself as apart from the 'norm', yet wanting to be seen as 'normal'. Ashley's key narrative of disassociation from her disability diagnosis resulted from her multiplicity of experiences; having a sister with profound intellectual disability, perceptions of her by others, perceptions of herself and her own disability experiences. The importance of these key events in her lived experiences, shape her narrative (Boenisch-Brednich, 2002). Ashley is in Turner's (1975) 'liminal space', a space of transition and transformation, where she stands on the threshold of a new landscape of experiences, moving across the limits of what she once was, into what she is going to be, but not yet knowing what that is. 


\section{References}

Agar, M. H. (1980). The professional stranger: An informal introduction to ethnography. San Diego: Academic Press.

Althusser, L. (2001). Lenin and philosophy and other essays, trans. B. Brewster. Retrieved from http://www.english.ufl.edu/mrg/readings/Lenin\%20and\%20Philosophy.pdf

Barker, P. (1990). Clinical interviews with children and adolescents. New York: Norton.

Bassey, M. (1999). Case Study Research in Education Settings. Ballmoor, Buckingham: Open University Press.

Baum, S. M., \& Olenchak, F. R. (2002). The Alphabet children: GT, ADHD, and more. Exceptionality: A Special Education Journal, 10(2), 77-91.

Birbeck, D. J., \& Drummond, M. J. N. (2007). Research with young children: Contemplating methods and ethics. Journal of Educational Enquiry, 7(2), 21-31.

Boenisch-Brednich, B. (2002). Migration and narration. Folklore, 20, 64-77.

Chase, S. E. (2003). Listening to people's stories: The use of narrative in qualitative interviews. In J. Elliott (Ed.), Using narrative in social research: Qualitative and quantitative approaches (pp. 17-35). Thousand Oaks, CA: SAGE Publications.

Clandinin, D. J. (2013). Engaging in narrative inquiry. Walnut Creek, CA: Left Coast Press.

Clandinin, D. J., \& Connelly, F. M. (1996). Teachers' professional knowledge landscapes: Teacher stories - stories of teachers - School stories - stories of schools. Educational Researcher, 25(3), 24-30.

Clandinin, D. J., \& Connelly, F. M. (2000). Narrative inquiry. San Francisco: Jossey-Bass.

Connelly, F. M., \& Clandinin, D. J. (1990). Stories of experience and narrative inquiry. Educational Researcher, 19(5), 2-14.

Connelly, F. M., \& Clandinin, D. J. (2006). Narrative inquiry. In J. L. Green, G. Camilli \& P. Elmore (Eds.), Handbook of complementary methods in education research (3rd ed., pp. 477487). Mahwah, NJ: Lawrence Erlbaum.

Craig, C. J. (2007). Story conselllations: A narrative approach to contextualising teachers' knowledge of school reform. Teaching and Teacher Education, 23, 173-188. doi: 10.1016/j.tate.2006.04.014

Cresswell, J. W. (2008). Educational research (3rd ed.). Upper Saddle River, NJ: Pearson Education.

DePoy, E., \& Gilson, S. (2010). Disability design and branding: Rethinking disability within the 21st Century. Maine and Astos, U.S.A.: Office of Special Education and Rehabilitative Services. Retrieved from http://www2.ed.gov/rschstat/research/.../nidrr-lrp-05-09-execsumm.pdf.

Dewey, J. (1997). Experience and education. New York, NY: Touchstone.

Duffy, M. (2011). Paul Ricoeur's Pedagogy of Pardon: A Narrative theory of memory and forgetting Retrieved from https://books.google.com.au/books?hl=en\&lr=\&id=4VLNM_dqrVUC\&oi=fnd\&pg=PP2\&dq $=$ narrative+as+cathartic\&ots=G4vr3oZZi5\&sig=ckFvyTa_U3HIJiqEYUYNzU0Oy$\mathrm{c \# v}=$ onepage \& $\mathrm{q}=\% 20$ cathartic $\& \mathrm{f}=$ false

Emden, C. (1998). Conducting a narrative analysis. Collegian, 5(3), 34-39.

Foley-Nicpon, M., Allmon, A., Sieck, B., \& Stinson, R. D. (2011). Empirical investigation of twice-exceptionality: Where have we been and where are we going? Gifted Child Quarterly, 55(1), 1-15. 
Foley-Nicpon, M., Assouline, S. G., \& Colangelo, N. (2013). Twice-exceptional learners: Who needs to know what? Gifted Child Quarterly, 57(3), 169-180. doi: $10.1177 / 0016986213490021$

Gagné, F. (2009). Building gifts into talents: Detailed overview of the DMGT 2.0 In B. MacFarlane \& T. Stambaugh (Eds.), Leading change in gifted education: The festschrift of Dr. Joyce VanTassel-Baska. Waco, TX: Prufrock Press.

Gubrium, J. F., \& Holstein, J. A. (2002). From the interview to the interview society. In J. F. Gubrium \& J. A. Holstein (Eds.), Handbook of interview research: Context and method (pp. 3-32). Thousand Oaks, CA: SAGE Publications.

Harrington, C., Foster, M., Rodger, S., \& Ashburner, J. (2013). Engaging young people with Autism Spectrum Disorder in research interviews. British Journal of Learning Disabilites, 41(3), 1-9.

Hill, M. (2005). Ethical considerations in researching children's experiences. In P. Christensen \& A. James (Eds.), Researching children's experiences: Approaches and methods (pp. 61-86). London, UK: SAGE Publications.

Kim, J. H. (2016). Understanding Narrative Inquiry: The Crafting and Analysis of Stories as Research. USA: SAGE Publications.

Kohler Riessman, C. (2008). Narrative Methods for the Human Sciences. Thousand Oaks, California: Sage Publications.

Mahoney, D. (2007). Constructing reflexive fieldwork relationships: Narrating my collaborative storytelling methodology. Qualitative Inquiry, 13(4), 573-594.

Martin, J., \& Merrotsy, P. (2006). Portfolio of artefacts: Promising data for qualitative research. Australasian Journal of Gifted Education, 15(1), 39-43.

Melson, G. F. (2001). Why the wild things are: Animals in the lives of children. Cambridge, MA: Harvard University Press.

Michailova, S., Piekkari, R., Plakoyiannaki, E., Ritvala, T., Mihailova, I., \& Salmi, A. (2014). Breaking the silence about exiting fieldwork: A relational approach and its implications for theorizing. Academy of Management Review, 39(2), 138-161. doi: 10.5465/amr.2011.0403

Munhall, P. L. (2001). Nursing research: A Qualitative perspective (3rd ed.). Sudbury, MA: National League for Nursing.

O’Haire, M. E., McKenzie, S. J., Beck, A. M., \& Slaughter, V. (2015). Animals may act as social buffers: Skin conductance arousal in children with Autism Spectrum Disorder in a social context. Developmental Psychobiology, 57(5), 584-595. doi: 10.1002/dev.21310

Patterson, W. (2013). Narratives of events: Labovian analysis and its limitations. In M. Andrews, C. Squire \& M. Tamboukou (Eds.), Doing narrative research (pp. 27-46). London: SAGE Publications.

Polkinghorne, D. E. (1988). Narrative knowing and the human sciences. Albany, NY: State University of New York Press.

Polkinghorne, D. E. (1995). Narrative configuration in qualitative analysis. Qualitative Studies in Education, 8(1), 5-23.

Polkinghorne, D. E. (2007). Validity issues in narrative research. Qualitative Inquiry, 13(4), 471486. doi: $10.1177 / 1077800406297670$

Preece, D., \& Jordan, R. (2010). Obtaining the views of children and young people with Autism Spectrum Disorders about their experiences of daily life and social care support. British Journal of Learning Disabilities, 38(1), 10-20.

Reis, S. M., Baum, S. M., \& Burke, E. (2014). An Operational definition of twice-exceptional learners: Implications and applications. Gifted Child Quarterly, 58(3), 217-230. doi: 10.1177/0016986214534976

Schuman, D. (1982). Policy analysis, education, and everyday life. Lexington, MA: Heath.

Seidman, I. (2006). Interviewing as qualitative research: A Guide for researchers in education and the social sciences (3rd ed.). New York, NY: Teachers College Press.

Turner, V. (1975). Dramas, fields and metaphores: Symbolic action in human societies. Ithaca: Cornell University Press. 
Wilson, C. J., \& Powell, M. B. (2001). A Guide to interviewing children: Essential skills for counsellors, police, lawyers and social workers. Crows, Nest, NSW, Australia: Allen \& Unwin.

World Health Organisation. (2011). World report on disability. Geneva, Switzerland: The World Health Organisation, United Nations.

Yin, R. K. (2009). Case study research: Design and methods (Vol. 5). Thousand Oaks, CA.: SAGE Publications.

Zwiers, M. L., \& Morrissette, P. J. (1999). Effective interviewing of children: A Comprehensive guide for counselors and human service workers. Philadelphia, PA: Taylor \& Francis. 